\title{
Habermas e o desafio pós-moderno (ainda)
}

Arthur Grupillo

PROFESSOR DO DEPARTAMENTO DE FILOSOFIA DA UFS

Num debate ocorrido da década de 1980 até mais ou menos os anos 2000, e que esfriou sem que tenha sido suficientemente resolvido, discutiu-se qual função a arte e a estética teriam na proposta de uma razão comunicativa, advogada por Habermas. Isso também pode ser formulado de outra maneira, a saber, qual implicação crítica teriam, para essa concepção de razão, a arte e a estética. Pois, se estas eram dificilmente incorporadas por um conceito subjetivo de razão, havia basicamente duas possibilidades: ou a razão comunicativa também era incapaz de incorporar a arte e a estética como parte da razão, incorrendo no mesmo problema que queria superar, ou ela era realmente capaz de fazer isso. Neste último caso, porém, não estava claro em que medida ela ainda permanecia razão, e não se transformava numa espécie de retórica. Martin Seel praticamente colocou um fim na discussão, quando desenvolveu sua tese de que: "Uma razão que não é estética, ainda não é nenhuma razão; a razão que se torna estética, já não é mais"

Habermas inicialmente havia tentado encontrar um lugar para a arte e a estética no que chamou de "racionalidade estético-expressiva", mas esbarrou nas críticas, que apontaram que essa tentativa levava a uma estética demasiado

${ }^{1}$ SEEL, Martin. Die Kunst der Entzweiung. Frankfurt am Main: Suhrkamp, 1997, p. 29 [,Vernunft, die nicht ästhetisch ist, ist noch keine; Vernunft, die ästhetisch wird, ist keine mehr."] 
expressivista e passava ao largo de toda uma discussão sobre a "verdade artística", isto é, de que a arte não pretende apenas dizer algo sobre o mundo subjetivo de alguém, mas tem potencial para sacudir também nossas convicçóes cognitivas e morais, estando assim relacionada à verdade. É então que uma importante concessão é feita aos críticos, e Habermas passa a considerar mais de perto a tese heideggeriana da arte como "abertura de mundo", não porém sem muitas ressalvas. Embora aquele debate tenha arrefecido, juntamente com a própria ideia de uma razão comunicativa, as condições em que ele se formou ainda se fazem sentir. Ainda continuamos nos debatendo, ao que parece, entre dois discursos filosóficos possíveis.

A maior das ressalvas é que, basicamente, a compreensão da linguagem e da poesia em Heidegger padece de uma hipóstase de sua função semântica ou, para dizer com Cristina Lafont $]^{2}$ de uma "absolutização" [Verabsolutierung] da função de abrir o mundo, gerando problemas estruturais, entre os quais o principal é a dificuldade de compatibilizar o conceito de mundo com o de ente intramundano que tem a função de abri-lo. Isto é, Heidegger não teria conseguido extirpar, pela raiz, a capacidade da linguagem de se referir aos entes, mesmo que sejam entes especiais como, em primeiro lugar, o próprio ser-aí, e posteriormente os signos linguísticos ou as próprias obras de arte e, entre estas, mesmo aquelas que não se referem a nada, como o templo grego. Por outro lado, além de conceder, contra os pressupostos de sua própria pragmática formal, a plausibilidade da discussão sobre a verdade artística, Habermas reconhece que "original é o uso que Heidegger faz desse conceito de mundo para uma crítica da filosofia da consciência”

Este conceito de verdade serve de fio condutor com o qual Heidegger introduz o conceito-chave da ontologia fundamental: o conceito de mundo. O mundo constitui o horizonte que abre o sentido, dentro do qual o ente, ao mesmo tempo, escapa e se manifesta ao ser-aí que cuida existencialmente do seu ser. $\mathrm{O}$ mundo sempre antecede ao sujeito que, agindo ou conhecendo, relaciona-se com objetos.

${ }^{2}$ Cf. LAFONT, Cristina. Sprache und Welterschließung. Zur linguistischen Wende der Hermeneutik Heideggers. Frankfurt am Main: Suhrkamp, 1994.

${ }^{3}$ HABERMAS, J. O discurso filosófico da modernidade. São Paulo: Martins Fontes, 2ooo, p. 209-IO. 
Não é o sujeito que estabelece relações com algo no mundo, mas é o mundo que, em primeiro lugar, institui o contexto a partir de cuja compreensão podemos deparar com o ente. (...) É óbvio o ganho, em termos de estratégia conceitual, diante da filosofia do sujeito: o conhecimento e a ação não precisam mais ser concebidos como uma relação sujeito-objeto. ${ }^{4}$

Este ganho conceitual, portanto, não poderá ser descartado - se Habermas pretende, também em seu projeto de uma razão comunicativa, escapar ao esquema sujeito-objeto -, permanecendo apenas o problema, não desprezível, das relações entre mundo e ente intramundano que se observa na estratégia de Heidegger de fornecer ao Ser o seu aí $(D a)$, o mundo aberto, que depois da chamada Kebre é atribuído à obra de arte:

Heidegger ontologizou decididamente a arte e apostou tudo em um movimento de pensamento destrutivamente libertador que deve superar a metafísica a partir de si mesma. Com isso, escapa das aporias de uma crítica autorreferencial da razão que tem de destruir seus próprios fundamentos. (...) Heidegger tenta romper o círculo mágico da filosofia do sujeito, liquefazendo temporalmente seus fundamentos. Mas o superfundamentalismo de uma história do Ser que abstrai de toda história concreta revela que ele permanece preso ao pensamento negados

Habermas precisa compatibilizar, portanto, dois aspectos deste argumento. Em primeiro lugar, a fim de escapar a uma crítica autodestrutiva da razão, ele concede premissas de uma ontologização da arte ou, pelo menos, de uma função poética da linguagem com forte tom antificcional. Do contrário, ele não pode, com os instrumentos da própria razão, dizer em que consiste a vida deformada por ela. Em segundo lugar, ele não pode, ao seguir esta via, simplesmente inverter a parte proscrita da imagem dialética, isto é, apontar de modo "superfundamentalista" o outro esquecido da razão, o que significaria, ainda que com os papéis

${ }^{4}$ Ibid., p. 208.

5 Ibid., p. I5o. 
invertidos, afirmar a mesma figura de pensamento ${ }^{6} \mathrm{O}$ fato é que esta inversão mostra, acima de tudo, a dificuldade de "nivelar o 'fenômeno estético' e equiparar a arte à metafísica” 7 Não por acaso, esta é uma outra deficiência, segundo Habermas, da compreensão heideggeriana da arte, que, ao contrário da maioria dos teóricos críticos, mal observou os esforços da arte de sua época: "Uma comparação com Walter Benjamin poderia mostrar quão pouco Heidegger foi influenciado pelas experiências genuínas da arte de vanguarda" ${ }^{8}$ Sendo assim, mesmo que não se possa simplesmente invertê-lo e identificá-lo com a verdade, o fenômeno estético continua sendo a via regia de uma crítica da razão que não se torna autodestrutiva. É no interior deste desafio, levantado na discussão com o

6 "Heidegger percebe o fracasso de sua tentativa de romper o círculo mágico da filosofia do sujeito; mas não percebe que esse fracasso é uma consequência daquela questão do Ser que só se pode pôr no horizonte de uma filosofia primeira, ainda que em guinada transcendental. A saída que se lhe oferece é uma operação que, com bastante frequência, repreendeu na 'inversão nietzschieana do platonismo': colocar a filosofia primeira de cabeça para baixo, sem se livrar de sua problemática” (Ibid., p. 2I4). De algum modo, porém, permanece a questão de saber se "filosofia do sujeito" e "filosofia primeira" são idênticos para Habermas. Curiosamente, a sessão intitulada "Prima philosophia como filosofia da consciência", em Pensamento pós-metafísico, não oferece material substantivo para melhor esclarecimento da questão. Cf. Id., Pensamento pós-metafísico. Rio de Janeiro: Tempo Brasileiro, 1990, p. 40-4I. Enquanto momento de reconstrução do pensamento metafísico, Habermas parte da convicção de Adorno de que o idealismo platônico tinha se enganado desde o início "pensando que as ideias ou formae rerum contêm realmente em si mesmas, como uma reduplicação, aquilo que elas produziram como sendo o material e o não-ente" (Ibid.). Isso teria ocorrido em virtude de um temor da antiga filosofia, ao voltar-se para o sujeito, para a identidade pura, de cair na condicionalidade do que é meramente subjetivo, noutras palavras, no relativismo subjetivista de Protágoras. Cf. também ADORNO, Th. "Zur Metakritik der Erkenntnistheorie. Drei Studien zu Hegel: Einleitung”. In: Gesammelte Schriften. Versão digital da edição das obras completas, sob licença da editora Suhrkamp. Berlin: Directmedia, 2003 (Digitale Bibliothek Band 97), p. 2214 (GS 5, S. 28). Habermas limitase a afirmar que "a filosofia idealista renova a ambos, o pensamento da identidade e a doutrina das ideias, na base da subjetividade, entrevista no momento da passagem do paradigma da ontologia para o do mentalismo. (...) [A razão moderna] assume a herança da metafísica na medida em que garante o primado da identidade frente à diferença e a precedência da ideia frente à matéria". (HABERMAS, op. cit., p. 4I) A resposta a esse "círculo mágico", que inclui tanto a inversão pósmoderna da filosofia primeira quanto a filosofia do sujeito, será o que Habermas designa como o seu renovado "pensamento pós-metafísico".

7 Id., 200o, p. I43.

${ }^{8}$ Ibid., p. I43. 
pensamento pós-moderno, que Habermas consolida, ambiguamente, sua visão da estética, deixando os rastros de uma lição que pode ser interessante para nós, mesmo hoje?

Talvez a obra mais difundida de Habermas, publicada em $1985, O$ discurso filosófico da modernidade é um exercício de diagnóstico de época. Fundamentalmente, o argumento de Habermas consiste na distinção entre dois discursos típicos a respeito dos "tempos modernos", que respondem a uma mesma conjuntura cultural. Partiremos primeiro da conjuntura para, em seguida, esclarecer os dois tipos de discurso.

Foi no domínio dos debates da crítica estética, no processo de distanciamento em relação a prescriçóes artísticas, que a famosa querelle des anciens et des modernes tomou consciência, pela primeira vez, "do problema de uma fundamentação da modernidade a partir de si mesma”, $\square^{10} \mathrm{O}$ partido dos modernos questionava o sentido de imitação dos modelos antigos, baseando-se no argumento histórico de um belo relativo, condicionado temporalmente, fundado em sua legalidade autônoma. "Para Baudelaire a experiência estética confundia-se, nesse momento, com a experiência bistórica da modernidade. $\mathrm{Na}$ experiência fundamental da modernidade estética, intensifica-se o problema da autofundamentação" m Assim como na querela de há pouco mais de três séculos, que toma uma forma culminante em Baudelaire, a querelle des modernes et postmodernes, empreendida intensivamente nos anos 70 do século XX, consolida filosoficamente, a partir de uma consciência histórica, argumentos esteticamente inspirados: $\mathrm{I}^{12}$ como o mostrou o estado da

9 A expressão "desafio pós-moderno" se tornaria, no âmbito das discussões da filosofia do discurso, relativamente frequente, embora algo imprecisa. Ela designa, sobretudo, o debate de Habermas com os representantes mais eminentes do pensamento de origem francesa, em $O$ discurso filosófico da modernidade. Cf. DUVENAGE, P. "The second phase continues: The postmodern challenge". In: Habermas and aesthetics: The limits of communicative reason. Cambridge: Polity Press, 2003, pp. 75-95; NASCIMENTO, Amós. Rationalität, Ästhetik und Gemeinschaft: Ästhetische Rationalität und die Herausforderung des Postmodernen Poststrukturalismus für die Diskursphilosophie. Tese (Doutorado em Filosofia) - Uni-Frankfurt, Frankfurt am Main, 2002.

${ }^{\text {Io }}$ HABERMAS, 20oo, p. 13 .

II Ibid., p. I4.

${ }^{12}$ Procuro parafrasear aqui a expressão particularmente feliz de Duvenage "asthetically informed arguments”. Cf. Op. cit., p. I. 
questão na arquitetura, onde primeiro se encontraram rupturas mais visíveis e maior articulação dos problemas teóricos ${ }^{\text {苟 }}$

Em resumo, os jovens arquitetos se viram entre uma redução do movimento moderno "a um sistema de preceitos formais" e "uma arquitetura mais humana, mais cálida, mais livre e mais diretamente relacionada com os valores tradicionais" "14 Importantes, para Habermas, são as soluções filosóficas por trás da polêmica estilística. "O que é comum aos 'ismos' que se formam com o prefixo 'pós' é o sentido do tomar distância" ${ }^{\text {II }} \mathrm{O}$ problema fundamental residiria numa experiência de descontinuidade, isto é, de que o pós-modernismo - ao contrário da palavra "pós-industrial”, por exemplo, que designa uma ampliação dos setores de prestação de serviços, mas sem questionar que o capitalismo "continuou a se desenvolver" - se transforma efetivamente num antimodernismo. Ora, a movimento da Ilustração, tendo rompido com o passado grego e cristão, sabia da sua consciência histórica, sem com isso ter se tornado "historicista", ou seja, sem distanciar o passado pela segunda vez, movimento pelo qual "o pluralismo estilístico, que até então fizera figura de incômodo, torna-se pois um trunfo". Daí a necessidade e a urgência do desafio: "por isso temos de enfrentar a questão acerca de nossa atitude diante desta descontinuidade nova e agora aberta"

${ }^{13}$ Cf. HABERMAS, "Arquitetura moderna e pós-moderna”. In: ARANTES, Otília \& ARANTES, Paulo. Um ponto cego no projeto moderno de Jürgen Habermas. São Paulo: Brasiliense, 1992; LYOTARD, J. “Notizen über die Bedeutung von 'post-'” In: Postmoderne für Kinder. Wien: Passagen, 1987, p. 99. Segundo Lucia Santaella, Federico de Oníz teria sido o primeiro a usar a expressão "pós-moderno", em sua introdução à Antología de la Poesia Española e Hipanoamericana, de 1934, que se tornaria corrente, a partir da década de 1970, tanto em teoria da literatura quanto da arquitetura. Cf. SANTAELLA, L. "Krise der Moderne?”. In: Mehrdeutigkeiten der Moderne. Kassel: Intervalle, Bd. I, 1998. Cf. também MAJETSCHAK, Stephan. "Jürgen Habermas und Jean-François Lyotard über Moderne und Postmoderne. Anmerkungen zu einer gescheiterten Debatte aus kunsttheoretischer Sicht”. In: Europäische Romane der Postmoderne. Frankfurt am Main: Peter Lang, 2004, pp. 37-5I.

${ }^{14}$ BENÉVOLO, L. Geschichte der Architektur des 19. und 20. Jahrbunderts . Apud HABERMAS, 1992, op. cit., p. 126.

Is Ibid., p. 126.

${ }^{16}$ Ibid., p. I29. O fato de que esta querela não é mais decidida apenas em revistas de arquitetura, mas no plano da consciência histórica, mostra-se também nas atuais discussões em filosofia da música. Já Adorno tinha observado o conflito entre o progresso e a restauração pri- 
Diante dessa conjuntura, Habermas diagnostica, como dissemos, dois discursos típicos, cujas principais inspirações seriam Hegel e Schelling. "Com a arquitetura historicista o idealismo abandonava as suas intençôes originárias. (...) A arquitetura historicista abandona esta ideia de reconciliação e o espírito, já não sendo força reconciliadora, passa a alimentar o dinamismo compensatório de uma realidade enfeitada e oculta por detrás das fachadas", ${ }^{17}$ Por outro lado: "Enquanto no Ocidente cristão os 'novos tempos' significavam a idade do mundo que ainda está por vir e que despontará somente com o dia do Juízo Final - como ocorre ainda na Filosofia das idades do mundo, de Schelling -, o conceito profano de tempos modernos expressa a convicção de que o futuro já começou: indica a época orientada para o futuro, que está aberta ao novo que há de vir" ${ }^{18}$ De fato, como afirma Duvenage, "no sistema de Schelling, não é o modelo de razão de Hegel, mas a poesia pública, que substitui o poder unificador da religião", ${ }^{19}$

De um lado, temos o contra-discurso da modernidade cindida de Hegel e, de outro, o antidiscurso esteticista da modernidade, que se move no âmbito da crítica anti-iluminista à razão levada adiante pelo romantismo. Habermas interpreta este último discurso como uma "mito-poética" filosoficamente inspirada, ligada a

mitiva na oposição entre Schoenberg e Stravinsky. Atualmente, a “impostação conservadora” é interpretada como mistura irônica de citações. V. Safatle considera que a discussão adorniana sobre Stravinsky é atual, “já que Stravinsky, de maneira sintomática, pode nos oferecer o quadro de compreensão para a racionalidade dos dispositivos formais que estruturam vários programaschave no interior do novo tonalismo. Há, por exemplo, uma linha reta que vai de Stravinsky até John Adams e Thomas Adès.” SAFATLE, V. Cinismo e falência da crítica. São Paulo: Boitempo, 2008, p. 195. O estilo musical chamado "novo tonalismo" seria caracterizado por uma indiferença em relação à resistência do material, com a consciência não-formalista de que, como "afirma Steve Reich: 'Para mim, princípios naturais de ressonância e da percepção musical humana não são limitações; são fatos da vida'.” (Ibid., p. 195). Há sem dúvida uma crítica possível a este diagnóstico, levando em conta a noção de limite a que está sujeita, não a razão subjetiva, mas a própria racionalidade comunicativa. A interpenetração de natureza e semântica, como sendo, de um lado, a resistência do material, como para Adorno, mas também como interpretação dessa resistência, pode ser capaz de mostrar que nem toda consciência de limites identifica-se simplesmente com autolimitação ou com indiferença, mas antes com uma experiência-limite ou, nas palavras de Reich, "fatos da vida".

${ }_{17}$ HABERMAS, 1992, p. 136-137.

${ }^{18}$ Id., 200o, p. 9.

19 DUVENAGE, op. cit., p. 77. 
uma determinada esperança messiânica, que haveria de se tornar, com Nietzsche, dionisíaca em vez de cristâ. ${ }^{20}$ Porém, o que é de extremo interesse, para nós, é que Habermas, mesmo colocando-se contra uma despedida apressada da modernidade, sempre foi um crítico das intenções originárias do idealismo a propósito de uma reconciliação universal, ao menos com os meios de que o idealismo dispunha. Além disso, enfatizou - no seu conceito de materialismo como complexidade hermenêutica - a importância de um espaço para o tipo de contingência histórica, aberta ao futuro e ávida por inovações, inclusive semântico-religiosas, a que o sistema de Hegel se furtava, sem mencionar seu próprio trabalho de juventude sobre a filosofia das idades do mundo de Schelling. Seria de esperar que Habermas compatibilizasse, da mesma forma, seu repúdio do antidiscurso esteticista da modernidade e sua crítica a Hegel, renovada com as seguintes palavras:

A racionalidade do entendimento, que a modernidade sabe que lhe é própria e reconhece como único vínculo, deve ampliar-se até a razão, seguindo os rastos da dialética do esclarecimento. Porém, como saber absoluto, essa razão assume, por fim, uma forma tão avassaladora que não apenas resolve o problema inicial de uma autocertificação da modernidade, mas o resolve demasiado bem [zu gut]: a questão sobre a autocompreensão genuína da modernidade submerge sob a gargalhada irônica da razão. Já que a razão ocupa agora o lugar do destino e sabe que todo acontecimento [Geschehen] de significado essencial já está decidido. Dessa maneira a filosofia de Hegel satisfaz a necessidade da modernidade de autofundamentação apenas sob o preço de uma desvalorização da atualidade e de um embotamento da crítica. ${ }^{21}$

${ }^{20}$ Cf. HABERMAS, 200o, p. 134 et seq: "Nietzsche se distancia desse pano de fundo romântico. A chave é oferecida pela comparação de Dioniso com Cristo, efetuada não apenas por Hölderlin, mas por Novalis, Schelling, Creuzer e em toda a recepção do mito no primeiro romantismo. Essa identificação do vertiginoso deus do vinho com o deus cristão salvador é possível apenas porque o messianismo romântico objetiva um rejuvenescimento, não uma despedida do Ocidente”.

${ }^{21}$ Ibid., p. 6o-6I. 
Dito de outro modo, interrogativo, como é possível a Habermas querer escapar da contradição performativa que reside no momento autodestrutivo da crítica da razão e, além disso, de uma reflexão absoluta intensificada, que desvaloriza a atualidade e embota a crítica do presente, levando em consideração aspectos de uma ontologização da arte que abre o mundo, sem com isso inverter, de modo fundamentalista, a estrutura aporética da filosofia do sujeito? É impressionante, no decorrer do Discurso filosófico da modernidade, a forma como Habermas reúne pensadores tão diferentes quanto Heidegger, Derrida, Foucault e Castoriadis sob uma mesma bandeira, a do antidiscurso da modernidade, que recairia na estrutura aporética da inversão. Entretanto, tendo em vista a crítica a Hegel, ele precisa assumir como desafio este discurso diante da possibilidade de uma crítica do presente, isto é, diante do potencial crítico da abertura de mundo, que sempre acontece de modo contingente, no conceito de uma modernidade aberta a inovações. Não nos orientamos aqui nem pela obra destes pensadores em particular nem pela justeza da interpretação que Habermas lhes concede, mas apenas na medida em que compóem, segundo ele, o antidiscurso da modernidade. Orientamo-nos por essa via, sobretudo, na medida em que todos são, como veremos, objetos da mesma caracterização circunscrita e criticada em Heidegger e, mesmo assim, assumida como um desafio.

Num dos principais pontos dessa discussão, Habermas entende, por exemplo, que a crítica de Derrida à escritura fonética visa à denúncia de uma escrita que "torna independente o dito em relação ao espírito do autor e ao alento do destinatário, assim como em relação à presença do objeto de que se fala. $\mathrm{O}$ medium da escritura confere ao texto sua autonomia pétrea em face de todos os contextos vivos" "22 Também essa tentativa, segundo Habermas, "não se desprende das pressóes do paradigma da filosofia do sujeito. Sua tentativa de suplantar Heidegger não escapa da estrutura aporética do acontecer da verdade esvaziado de toda validade da verdade" ${ }^{23}$ Aqui, Habermas opóe explicitamente a validade da verdade [Wabrheitsgeltung] ao acontecer da verdade [Wabrbeitsgeschehens]. Não obstante, ele precisa reconhecer, em benefício de seu próprio projeto de uma pragmática discursiva, que essa crítica de Derrida ao "platonismo do significado"

\footnotetext{
${ }^{22}$ Ibid., p. 233.

${ }^{23}$ Ibid., p. 234.
} 
é justa: "Com razão, Derrida censura o fato de que, desse modo, a linguagem fique reduzida àquelas partes úteis para o conhecimento ou para a fala que constata fatos. A lógica tem prioridade sobre a gramática, a função cognitiva sobre a função do entendimento intersubjetivo" ${ }^{24}$ Em particular, o debate com Derrida tem uma importância adicional por enriquecer as discussóes levantadas no contexto do Primeiro Interlúdio da Teoria da ação comunicativa a propósito da tese de Tugendhat, segundo a qual todo enunciado em primeira pessoa pode ser transformado num enunciado objetivo, o que tornaria difuso, do ponto de vista de uma estética da verdade, o limite entre uma linguagem subjetiva ou ficcional e uma linguagem "séria".

No Excurso sobre o nivelamento da diferença de gênero entre filosofia e literatura, Habermas afirma que "Derrida quer estender a soberania da retórica sobre o domínio da lógica para resolver o problema diante do qual se encontra a crítica totalizante da razão", ${ }^{25}$ o que definitivamente não é uma estratégia conceitual completamente estranha ao próprio Habermas. A dificuldade residiria apenas - o que também não é pouco - numa assimilação da crítica da razão à crítica literária. O problema que Adorno reconhece como inevitável é, entretanto, encoberto por Derrida como sendo "desprovido de objeto", visto que "a empresa desconstrutivista não se deixa comprometer com as obrigações discursivas da filosofia e da ciência", ${ }^{26}$ isto é, abdica de qualquer pretensão cognitiva ${ }^{27}$ No entanto, como Habermas pode sair da aporia da autorreferencialidade sem transferir, pelo menos em parte, para a retórica, a crítica da razão? Talvez o ponto-chave da questão consista menos na concessão de uma capacidade poética da linguagem, o que o próprio Habermas faz, do que numa absolutização da sua função de abrir o mundo.

$\mathrm{Na}$ controvérsia entre Derrida e Searle, retomada por Habermas, renova-se o debate em torno do caráter parasitário dos modos fictícios, simulados ou indiretos de emprego da linguagem. Enunciada por um ator sobre o palco, como elemento

\footnotetext{
${ }^{24}$ Ibid., p. 243.

${ }^{25}$ Ibid., p. 264.

${ }^{26}$ Ibid., p. 265.

${ }^{27}$ Sobre as diferenças entre Adorno e Derrida, Cf. MENKE-EGGERS, C. Die Souveränität der Kunst. Ästhetische Erfabrung nach Adorno und Derrida. Frankfurt am Main: Athenäum,
} 1988. 
de uma poesia ou ainda no interior de um monólogo, uma promessa torna-se, como afirma Austin, "particularmente vazia e nula.' ${ }^{28}$ Contudo, é preciso esclarecer o que se entende por uso "sério" da linguagem. Se colocarmos sob esta categoria os usos da linguagem voltados ao entendimento, também os modos fictícios, quando empregados corretamente em seus contextos - por exemplo, a fala de um ator no palco - são, em determinado sentido, muito "sérios". Diálogos ou monólogos, seja no teatro, no cinema ou na literatura, não "enganam”, mas trazem à tona muito seriamente, inclusive na comédia, a inserção da linguagem no seu contexto, a sua margem de variação, os seus usos possíveis, os conflitos comunicativos, a possibilidade de mal-entendidos, ambiguidades, etc., o que, de certa forma, nos abre os olhos para os enganos da linguagem. ${ }^{29}$ "Essa variação de contexto, que afeta o significado, não pode, em princípio, ser detida ou controlada, já que os contextos não podem ser esgotados teoricamente, isto é, dominados de uma vez por todas" ${ }^{30}$ Agora, se entendemos por emprego "sério" da linguagem apenas aqueles, como pretende Habermas, que são "eficientes para a ação", corremos o risco de causar um curto-circuito entre fim ilocucionário e interesse perlocucionário, de implodir completamente a diferença entre ação comunicativa e ação estratégica, sem a qual a suposta razão comunicativa é apenas uma razão subjetiva sofisticada.

A "coordenação" da ação através de um uso estratégico da linguagem ultrapassaria o limite de um emprego sério, pois "sério" significaria aqui justamente a dissimulação do caráter fictício do fim ilocucionário. $\mathrm{Na}$ arte, acontece o oposto, ou seja, o tornar patente do caráter fictício de um emprego linguístico, a fim de trazer à tona aspectos de sua função poética que, por assim dizer, subjaz aos

${ }^{28}$ HABERMAS, 2000, p. 273. Para um desenvolvimento desta mesma problemática, cf. "Filosofia e ciência como literatura?". In: Id., 1990, pp. 235-255.

${ }^{29}$ Cf. HESS-LÜTTICH, Ernst W.B. Kommunikation als ästhetisches Problem. Tübingen: Narr, 1984. Além dos exemplos significativos explorados nos diálogos de Kafka, ou mesmo no realismo de Brecht, observem-se também certos diálogos cômicos, baseados na imitação e na caricatura, onde é possível experimentar um tipo de catarse baseada no "desmascaramento do ridículo", no momento em que a verdade vem à tona. O desmascaramento do falso "marquês", em As preciosas ridiculas, dos falsos "médicos", em O doente imaginário, ou do falso "beato moralista”, em Tartufo, só para citar Molière. Cf. GRUPILLO, A. "A urbanização da província”: Molière e a categoria do ridículo. In: Artefilosofia, Ouro Preto, n.3, jul. 2007, p.193-200.

${ }^{30}$ HABERMAS, 200o, p. 276. 
demais empregos da linguagem. Quando se afirma, seguindo a perspectiva de Derrida, e com razão, que "se não fosse possível a um personagem em uma peça de teatro fazer uma promessa, não haveria promessas na vida real”, disso não se segue, de nenhum modo, que "o comportamento sério é a representação de um papel dentre outros" " ${ }^{11}$ A pretensão de verdade levantada pelas obras de arte é um potencial para desvelar precisamente na medida em que coloca o expectador diante do jogo entre aparência e verdade sendo, neste caso, uma espécie de "aviso", de "advertência" sobre a possibilidade de um uso "fictício", isto é, "estratégico" nos empregos linguísticos que se dão fora do palco. É nisto que consiste seu potencial cognitivo.

Habermas entende, de modo um pouco reducionista, que as restrições, sob as quais os atos ilocucionários implicam uma força coordenadora e possuem consequências relevantes para a ação, definem o domínio de um uso "normal" da linguagem. "Tais restrições podem ser analisadas como aquelas pressuposições idealizantes que temos de efetuar na ação comunicativa.' '] Mais do que as pressuposiçôes idealizantes, o que permite delimitar o campo de um emprego "sério" e não parasitário da linguagem é o uso linguístico correto em seu contexto, que fornece as condiçóes pressupostas como "normais" em uma comunidade linguística. Sempre podemos falar de um emprego correto de um ato de fala no palco, na medida em que "quando a linguagem cumpre uma função poética, realiza-a em uma relação reflexiva da expressão linguística consigo mesma” "3ão por acaso, o conceito de uma função poética da linguagem pode ser de especial interesse contra uma absolutização da função de abrir o mundo. Aqui, entra em jogo o esquema funcional de Roman Jakobson, que enriquece as funções básicas estabelecidas por Bühler ${ }^{34}$ Segundo Jakobson:

Toda tentativa de reduzir a esfera da função poética à poesia ou de limitar a poesia à função poética seria uma simplificação enganosa. A função poética não representa a única função da arte da palavra, mas apenas uma função dominante estruturalmente determinante,

\footnotetext{
${ }^{3 \mathrm{I}}$ Ibid., p. 274.

${ }^{32}$ Ibid., p. 275.

33 Ibid., p. 28 o.

${ }^{34}$ Cf. BÜHLER, Karl. Teoria del Lenguaje. Madrid: Revista de Occidente, I96I.
} 
enquanto em todas as outras atividades linguísticas desempenha um papel subordinado e complementar. Ao dirigir a atenção para o lado sensivel dos signos, essa função aprofunda a dicotomia fundamental entre signos e objetos. Por esse motivo, caso investigue a função poética, a linguística não pode restringir-se ao campo da poesia. ${ }^{35}$

A abordagem de Jakobson é mais complexa do que se supóe à primeira vista. De um lado, ela concede que a função poética da linguagem está presente em todos os usos linguísticos, sendo impossível, através de pressupostos idealizadores quaisquer, extirpar pela raiz esta referência do uso linguístico ao seu emprego correto em situaçôes comunicativas. No entanto, ele é rigoroso em afirmar que "na arte da palavra”, embora as outras funções linguísticas também estejam presentes, a função poética é a dominante. Por fim, ele insiste em que a linguística não pode restringir a investigação da função poética da linguagem apenas à poesia; faz isso, contudo, sem hipertrofiar esta função a ponto de converter toda linguagem em uma variante dos modos fictícios de emprego. Até porque, com isso, se perderia também a pretensão de verdade erguida com a própria função poética. Jakobson conclui que não se pode reduzir a função poética à poesia nem tampouco a poesia à função poética. O fundamental, aqui, é que embora se dirija ao medium linguístico enquanto tal a função poética não elimina a distinção entre signo e referência - ou entre mundo e ente intramundano, para usar outro vocabulário - mas antes "aprofunda" a dicotomia fundamental entre signos e objetos. Por isso, as forças coordenadoras da ação, que estão neutralizadas na compreensão da arte e da poesia como "abertura de mundo", são apenas enfraquecidas no conceito de uma função poética da linguagem ${ }^{36}$ Isso significa que, mesmo no uso linguístico voltado à coordenação das ações, é preciso se movimentar numa função poética da linguagem que não coordena nada, mas situa os participantes

35 JAKOBSON, R. "Linguistik und Poetik". In: Poetik. Frankfurt am Main: Suhrkamp, 1979, p. 92. Apud HABERMAS, 2000, p. 28I.

${ }^{36}$ Daí James Bohman poder dizer que "Habermas está, portanto, errado em corrigir sua intuição prévia de que a abertura [ disclosure] está ligada à "função poética” da linguagem de Jakobson e introduzir uma função de abertura de mundo distintivamente heideggeriana.” BOHMAN, J. "World disclosure and radical criticism". In: Thesis eleven, 1994, n. 37, p. 90. 
numa linguagem. Entretanto, embora se apoie explicitamente no esquema de Jakobson em sua crítica a Derrida, Habermas permanece vinculado ao conceito de Heidegger:

Na modernidade, diferenciaram-se "esferas de valor" a partir de cada um desses momentos - a saber, a arte, a literatura e a crítica especializada em questóes de gosto, sobre o eixo da abertura do mundo, por um lado, e os discursos ligados a soluçôes de problemas e especializados em questóes de verdade e justiça, sobre o eixo de processos de aprendizado intramundanos, por outro ${ }^{37}$

Este modo de conceituação estranha, pois o conceito de abertura de mundo, enquanto acontecimento da verdade, opóe-se explicitamente à validade da verdade, consequentemente, ao conceito de uma esfera de valor. Além disso, convém ressaltar, ainda que brevemente, um outro aspecto do desafio colocado pelo antidiscurso da modernidade. O modelo da "inversão" da razão, ou da relação da razão com o seu outro, revela uma metafórica de cisão e exclusão que se torna mais clara no debate de Habermas com Foucault, o qual passaremos em revista. Tal discussão permite ver, ao mesmo tempo, quão difícil é a empresa filosófica de Habermas, e quais obstáculos ele teria ainda de superar.

Habermas sempre chamou atenção para os problemas lógicos da crítica da razão. Quando esta é levada a cabo com os instrumentos da própria razão, já o sabemos, incorre na contradição performativa de uma petição de princípio, assumida e aceita por Horkheimer e Adorno. Quando, por outro lado, é buscada num discurso diferenciado, indireto, carente de pretensões racionais, recai numa inversão da filosofia do sujeito ou, mais precisamente, numa inversão fundamentalista da razão, que não pode explicitar seus fundamentos normativos. Sem querer entrar nos méritos da teoria do poder de Foucault, que Habermas critica,

37 HABERMAS, 200o, p. 47I. E isso depois de ele mesmo, Habermas, ter verificado que "Heidegger se contenta em indicar, de modo global, a linguagem como a morada do Ser; apesar da posição privilegiada atribuída à linguagem, nunca a investigou sistematicamente.” (Ibid., p. 230). Observe-se que a crítica de um déficit linguístico em Heidegger é semelhante à de um déficit sociológico em Adorno, isto é, refere-se a de uma hipertrofia da pretensão do discurso filosófico e uma falta de diálogo com as ciências, na nova figura de um pensamento "pós-metafísico". 
interessa-nos aqui explorar as consequências metodológicas de uma alteridade enfática entre a razão e o seu outro, particularmente visível no "interesse filosófico pela loucura como um fenômeno complementar da razão" "38

Conquanto reconheça que, por certo, as análises de Foucault são mais ricas e simplesmente mais informativas que as explanaçóes de Heidegger e Derrida sobre a técnica, por se movimentarem no âmbito objetivo da historiografia empírica e erudita. ${ }^{39}$ Habermas pode, mediante a localização de uma aporia metodológica, equiparar novamente Foucault a Heidegger:

Por um lado, Foucault tem de conservar, no conceito de um poder que se oculta ironicamente no discurso como vontade de verdade e que ao mesmo tempo sobressai, o sentido transcendental das condiçôes de possibilidade da verdade. Por outro, não somente opóe ao idealismo do conceito kantiano uma temporalização do a priori - de modo que as novas formaçóes discursivas, que substituem as antigas, possam emergir como eventos [Ereignisse] - mas, mais ainda, despoja o poder transcendental das conotações que Heidegger prudentemente reserva a uma história aurática do Ser. Foucault não apenas historiciza como, ao mesmo tempo, procede de maneira nominalista, materialista e empirista, ao pensar as práticas transcendentais de poder como o particular, resistente a todo universal, como o inferior, o sensível-corporal, o que escapa a todo inteligível $4^{40}$

Com efeito, a aporia só se sustenta porque essas práticas transcendentais destranscendentalizadas - este é o paradoxo -, a contrário do que Habermas pensa, não são completamente ininteligíveis. Apenas ele quer chamar atenção para um determinado tom da retórica foucaultiana, em relação à qual a de Heidegger seria

$3^{8}$ Ibid., p. 335. Ou, como ele diz, implicando-se no problema, que "o louco e o criminoso só podem desdobrar essa força da negação ativa, como razão invertida [verkehrte Vernunft], portanto, graças aos momentos separados da razão comunicativa.” (Ibid., p. 336, nota 3 ) Que quer isto dizer? Que a razão comunicativa incorpora inclusive um elemento de loucura?

${ }^{39}$ Cf. Ibid., p. 470.

${ }^{40}$ Ibid., p. 359. "Ereignisse" em itálico no original. 
mais difícil de denunciar, como prossegue o texto: "Na última filosofia de Heidegger, não são fáceis de estabelecer as consequências paradoxais de um conceito fundamental contaminado de significações contrárias, visto que a recordação do ser imemorial foge ao juízo formulado com base em critérios verificáveis" ${ }^{41} \mathrm{O}$ gesto metodológico de Foucault, que precisamente se tinha tornado elogiável, transforma-se em motivo para a crítica ${ }^{42}$ O que está em jogo, aqui, são novamente as intersecçôes entre mundo e ente intramundano, entre as condições de possibilidade transcendentais e uma abordagem concreta. Em uma formulação posterior, Habermas reconhecer que:

Heidegger faz justiça - na forma de uma historicização do a priori do sentido - à destranscendentalização da espontaneidade geradora do mundo, sem precisar enfrentar consequências aporéticas. De um lado, ele mantém, com a diferença transcendental entre mundo e intramundano, a diferença metodológica entre investigaçóes ontológicas e ônticas. 43

E, de fato, é preciso reconhecer, Heidegger é tão fiel à diferença ontológica, que se tem muitas dificuldades em localizar, em sua obra, intersecções aporéticas entre mundo e ente intramundano. Uma possibilidade residiria, talvez, precisamente na sua abordagem da origem da obra de arte, que abre o mundo ao mesmo tempo em que parece poder ser encontrada, como ente, no mundo por ela mesma aberto. Habermas não julga ter as mesmas dificuldades quando formula suas objeçôes lógicas a Foucault. Aquilo que em Heidegger aparece como diferença

${ }^{4 \mathrm{I}}$ Ibid..

42 "Em suma, a genealogia das ciências humanas de Foucault apresenta-se em um papel duplo desconcertante. Por um lado, desempenha o papel empirico de uma análise das tecnologias de poder que devem explicar o contexto funcional social da ciência do homem; aqui as relaçóes de poder interessam enquanto condições de nascimento e enquanto efeitos sociais do saber científico. Essa mesma genealogia desempenha, por outro lado, o papel transcendental de uma análise das tecnologias de poder, que devem explicar como os discursos científicos sobre o homem são de modo geral possíveis.” (Ibid., p. 384)

${ }^{43}$ Id., Verdade e justificação. São Paulo: Loyola, 2004, p. 33. 
ontológica, em Foucault é denunciado como "fusão da noção idealista de síntese transcendental com os pressupostos de uma ontologia empírica" ${ }^{44}$

É precisamente essa fusão que Habermas quer evitar e, por isso, é obrigado a assumir, com Heidegger, que: "A história dos transcendentais e da transformação dos horizontes de abertura do mundo exigem conceitos distintos daqueles que são próprios ao ôntico e ao histórico. É nesse ponto que os caminhos se bifurcam”, 45 Noutras palavras, embora toda a objeção aos déficits ônticos de Heidegger, que teriam sido supridos pelas investigaçóes linguísticas de Derrida e pela historiografia concreta de Foucault, Habermas considera mais consistente a base conceitual que parte de uma diferença ontológica, isto é, que não confunde o conceito de mundo com o de ente intramundano, nem as estruturas transcendentais com as histórico-concretas ${ }^{46}$ Não obstante, Habermas procurará manter esta diferença sem consumir a validade no conceito de sentido. Evita a fusão para possibilitar uma relação entre o a priori de sentido da linguagem e os processos de aprendizado intramundanos, ainda que pareça uma ideia dissonante atribuir ao primeiro o privilégio de uma determinada "esfera" de valor.

Em resumo, o imenso problema que Habermas assume, e que parece não ter sido suficientemente resolvido, é que as intersecções entre mundo e ente intramundano não poderiam hipostasiar uma semântica da abertura de mundo a ponto de obstruir uma referência, filosoficamente produtiva, ao ente intramundano, mas também não poderiam fundir o condicionado com as condiçóes, efetuando "uma fusão de significados opostos" ${ }^{47}$ Parece permanecer aí apenas

${ }^{44}$ Id., 200o, p. 384. A distinção entre a origem [Ursprung] heideggeriana e o conceito de procedência [Herkunft] que a genealogia herda de Nietzsche, é especialmente elaborada no conhecido ensaio: FOUCAULT, M. "Nietzsche, genealogy, history". In: Language, counter-memory, practice - Selected essays and interviews. Ithaca: Cornell University Press, 1977.

${ }^{45}$ HABERMAS, 20oo, p. 357

${ }^{46} \mathrm{E}$, contudo, ambas as perspectivas parecem seguir, para ele, o mesmo caminho de um antidiscurso filosófico da modernidade, que já tinha se bifurcado uma primeira vez entre, de um lado, um pensamento da finitude e, de outro, "De Hegel a Merleau-Ponty, (...) tentativas de superar esse dilema em uma disciplina que unifique os dois aspectos e de compreender a história concreta das formas a priori enquanto um processo de autocriação do espírito e do gênero.” Tentativas que encarnariam "a utopia do autoconhecimento completo". (Ibid., p. 368)

${ }^{47}$ Ibid., p. 358. 
uma boa intenção filosófica, possivelmente fora de alcance para um pensamento pós-metafísico, mas ainda valiosa como diagnóstico de época.

\section{Referências}

ADORNO, Theodor. "Zur Metakritik der Erkenntnistheorie. Drei Studien zu Hegel: Einleitung”. In: Gesammelte Schriften. Versão digital da edição das obras completas, sob licença da editora Suhrkamp. Berlin: Directmedia, 2003 (Digitale Bibliothek Band 97).

BOHMAN, James. "World disclosure and radical criticism". In: Thesis Eleven I994, n.37.

BÜHLER, Karl. Teoría del lenguaje. Tradução de Julián Marías. Madrid: Revista de Occidente, I96I.

DUVENAGE, Pieter. Habermas and aesthetics: The limits of communicative reason. Cambridge: Polity Press, 2003.

FOUCAULT, Michel. "Nietzsche, genealogy, history”. In: Language, countermemory, practice - Selected essays and interviews. Ithaca: Cornell University Press, 1977.

GRUPILLO, Arthur. "A urbanização da província”: Molière e a categoria do ridículo. In: Artefilosofia, Ouro Preto, n.3, jul.2007, p.193-200.

HABERMAS, Jürgen. "Arquitetura moderna e pós-moderna". Tradução de Márcio Suzuki. In: ARANTES, Otília \& ARANTES, Paulo. Um ponto cego no projeto moderno de Jürgen Habermas. São Paulo: Brasiliense, 1992. - O discurso filosófico da modernidade. Tradução de Luiz Sérgio Repa e Rodnei Nascimento. São Paulo: Martins Fontes, 2000. . Pensamento pós-metafísico. Tradução de Flávio Beno Siebeneichler. Rio de Janeiro: Tempo Brasileiro, I990.

. Verdade e justificação. Tradução de Milton Camargo Mota. São

Paulo: Loyola, 2004.

HESS-LÜTTICH, Ernst W. B. Kommunikation als ästhetisches Problem. Tübingen: Narr, 1984.

JAKOBSON, Roman. "Linguistik und Poetik". In: Poetik. Frankfurt am Main: Suhrkamp, 1979. 
LAFONT, Cristina. Sprache und Welterschließung. Zur linguistischen Wende der Hermeneutik Heideggers. Frankfurt am Main: Suhrkamp, 1994.

LYOTARD, Jean-François. "Notizen über die Bedeutung von 'post-'” In: Postmoderne für Kinder. Wien: Passagen, 1987.

MAJETSCHAK, Stephan. "Jürgen Habermas und Jean-François Lyotard über Moderne und Postmoderne. Anmerkungen zu einer gescheiterten Debatte aus kunsttheoretischer Sicht”. In: Europäische Romane der Postmoderne. Frankfurt am Main: Peter Lang, 2004.

MENKE-EGGERS, Christoph. Die Souveränität der Kunst. Ästhetische Erfahrung nach Adorno und Derrida. Frankfurt am Main: Athenäum, 1988.

NASCIMENTO, Amós. Rationalität, Ästhetik und Gemeinschaft: Ästhetische Rationalität und die Herausforderung des Postmodernen Poststrukturalismus für die Diskursphilosophie. Tese (Doutorado em Filosofia) - Uni-Frankfurt, Frankfurt am Main, 2002.

SAFATLE, Vladimir. Cinismo e falência da crítica. São Paulo: Boitempo, 2008. SANTAELLA, Lucia. "Krise der Moderne?”. In: Mebrdeutigkeiten der Moderne. Kassel: Intervalle, Bd. I, 1998.

SEEL, Martin. Die Kunst der Entzweiung. Frankfurt am Main: Suhrkamp, 1997.

Resumo: Trata-se de discutir as dificuldades de compatibilizar alguns pressupostos da filosofia de Jürgen Habermas. Ela pretende escapar a uma crítica autodestrutiva da razão, ao mesmo tempo em que concede premissas de uma ontologização da arte ou, pelo menos, de uma função poética da linguagem com forte tom antificcional. Por outro lado, ela não pode, ao seguir esta via, simplesmente inverter a parte proscrita da imagem dialética, isto é, apontar de modo "superfundamentalista" o outro esquecido da razão. Isso permite
Abstract: We try to discuss the difficulties to reconcile some assumptions of Jürgen Habermas' philosophy. It intends to escape a self-destructive critique of reason, while at the same time granting premises for an ontologization of art or, at least, for a poetic function of language with a strong antifictional tone. On the other hand, it cannot, by following this path, simply invert the proscribed part of the dialectical image, that is, point out in a 'superfundamentalist' way the forgotten other of reason. This allows us to see 
perceber como sua filosofia segue ex- how his philosophy remains exposed posta ao desafio colocado pelo pensa- to the challenge posed by postmodern mento pós-moderno. thought.

Palavras-chave: Habermas; Keywords: Habermas; ModerModernidade; Pós-modernidade; Arte; nity; Postmodernity; Art; Aesthetics. Estética. 